\title{
Pavement Condition and Crashes
}

David Levinson, Toshihiro Yokoo ${ }^{\dagger}$, Mihai Marasteanu ${ }^{\ddagger}$

Keywords: weather, pavement condition, traffic safety

https://doi.org/10.32866/5771

Transport Findings

This paper combines GIS data on crashes with a separate GIS database on pavement quality to test the relationship between pavement quality and crashes over 12 years. Poor road quality is associated with more property damage and injury crashes. The interaction of road quality and curves was surprising, indicating that good pavement quality on curves was associated with an increase in the fatal, injury, and property-damage crash rate.

\section{RESEARCH QUESTION AND HYPOTHESES}

It has been posited that poor pavement quality reduces the ability of roads to drain and reduces the ability of vehicles to resist skidding, and is thus associated with more crashes. Previous research has found that crash rate depends on both pavement type and pavement condition (Buddhavarapu, Banerjee, and Prozzi 2013; Al-Masaeid 1997; Abdel-Aty and Abdalla 2004; Lee, Nam, and AbdelAty 2015; Najafi, Flintsch, and Medina 2017; Merritt et al. 2015; Elghriany 2016; Vinayakamurthy, Mamlouk, and Underwood 2017; Chan et al. 2009).

Our research tests the relationship between number of crashes and road quality using data from Minnesota, while controlling for traffic data (annual average daily traffic (AADT) and percent truck), segment length, crash conditions (date, road characteristics, and road surface), and pavement type. We test the hypothesis that higher quality roads have fewer crashes.

\section{DATA AND METHODS}

This research uses pavement quality data and crash data from the Minnesota Department of Transportation (MnDOT). Pavement quality data is available from 2000 to 2015, the crash data from 2003 to 2014. Therefore, we use the data from 2003 to 2014 in order to analyze the relationship between incident number and road quality. While MnDOT's crash data is recorded for all road sections in Minnesota, pavement quality data is only available for selected road segments (state and county highways).

The crash data is a GIS shapefile and contains information about each crash including: location, crash date, severity of crash, crash type, road characteristics, road design, and weather condition.

\footnotetext{
* Transport Lab, University of Sydney ORCID iD: 0000-0002-4563-2963 Link: http://transportist.org

† West Nippon Expressway Company

‡ Civil Engineering, University of Minnesota ORCID iD: 0000-0001-8331-4504
} 


\begin{tabular}{|c|c|c|c|c|c|}
\hline Year & Buffer size & Total crash (A) & Points in polygon (B) & \# of Error (B-A) & Error rate \\
\hline 2004 & $10 \mathrm{~m}$ & 39,010 & 44,993 & 5,983 & $15.3 \%$ \\
\hline 2004 & $5 m$ & 38,465 & 43,224 & 4,759 & $12.4 \%$ \\
\hline 2004 & $3 m$ & 38,292 & 42,700 & 4,408 & $11.5 \%$ \\
\hline 2004 & $1 \mathrm{~m}$ & 38,129 & 41,900 & 3,771 & $9.9 \%$ \\
\hline 2004 & $0.1 \mathrm{~m}$ & 37,378 & 39,251 & 1,873 & $5.0 \%$ \\
\hline 2004 & $0.001 \mathrm{~m}$ & 36,388 & 37,143 & 755 & $2.1 \%$ \\
\hline 2004 & $0.0001 \mathrm{~m}$ & 32,303 & 32,343 & 40 & $0.1 \%$ \\
\hline 2004 & $0.00001 \mathrm{~m}$ & 29,581 & 29,581 & 0 & $0.0 \%$ \\
\hline
\end{tabular}

The pavement quality data records pavement roughness and surface distress information for each year. AADT and percent truck on each segment are also collected. We also received an electronic highway map from MnDOT, which has highway segment information.

Several standard indicators of pavement quality (Surface Rating (SR), International Roughness Index (IRI), Pavement Quality Index (PQI)) are provided, but we focus on the Ride Quality Index (RQI). RQI ranges from 0-5 and indicates the smoothness of the pavement, with 5 indicating smoother. The correlation between the alternative pavement quality indices are high (RQI and SR: 0.55, PQI and SR: 0.89, PQI and RQI: 0.85, RQI and IRI: -0.97), so we use only RQI as an independent variable describing pavement quality.

To manage the data, we use QGIS version 2 (Sutton and Dassau 2015), an open source geographic information system. The crash data is recorded as points and the pavement quality data is recorded on mile-by-mile basis. We match these two data using QGIS.

In brief, we select for crashes by year. There are around 15,900 crashes per year, 190,918 in total. We aim to select crashes only on state highways for which pavement quality data is available (Figure 1). We count the crashes on each segment by severity level (1: Incapacitating Injury, 2: Non-incapacitating Injury, 3: Possible Injury, 4: Fatal, 5: Property Damage, 6: No Value). The count depends on the GIS buffer around the road, tighter buffers remove crashes from the data set, (Table 1) ultimately we use a buffer of $0.00001 \mathrm{~m}$ (i.e. only accepting crashes that were accurately geocoded), preferring elimination of false positives to the presence of false negatives. Then we merge the crash data with the pavement quality data.

We analyze RQI for each year on a mile-by-mile basis, and control for traffic, share of trucks, pavement type, highway geometry, weather conditions, day-ofweek, month-of-year, and time-of-day. The dependent variable is the number of crashes on each segment in each year (distinguished for each severity level). Number of crashes by severity is given by $\left(\mathrm{Crash}_{S}\right)$ where $(S=$ Fatal, Injury, or 


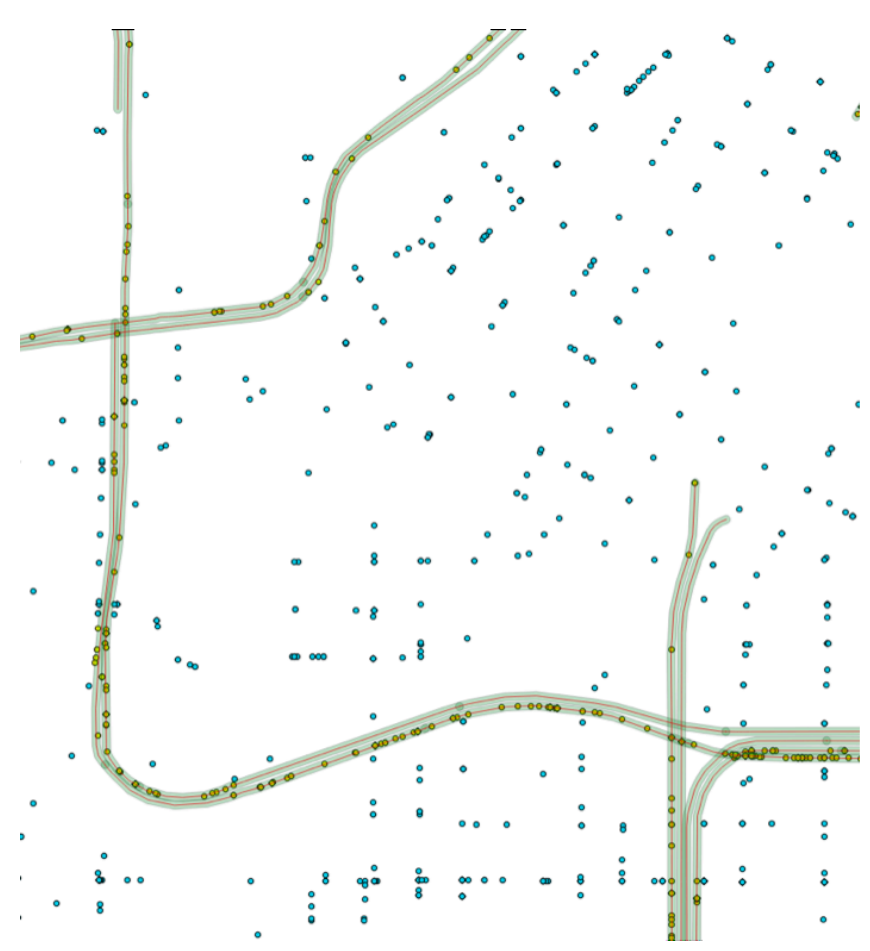

Figure 1: Crash data (a) original and (b) after processing of Select by location

CURVE ANO NEVEL NOT SPECIFIED NOT SPECIFIED NOT SPECIFIED C CURVE AND LEVELNOT SPECIFIED STRAIGHT AT HILLCRESTSTRAIGHT AT HILLCREST

Property damage). Many segments had no crashes in a given year. Injury is the sum of Incapacitating Injury, Non-incapacitating Injury, and Possible Injury. Table 2 lists the independent variables.

In order to avoid the dummy variable trap, we drop one category from the model for variables which would otherwise be determined, in this case, Year: 2014 and Pavement type: concrete. 
Table 2: List of Independent variables

\begin{tabular}{|c|c|}
\hline Variables & Definition \\
\hline Trucks & Percentage of truck volume among total traffic volume \\
\hline Traffic & Annual average daily traffic (AADT) \\
\hline Length & Segment length (miles) \\
\hline Bituminous $_{1}$ & $\begin{array}{l}\text { Indicator, } 1=\text { pavement type is BAB, BFD, or BOB, (BAB: Bituminous Aggregate Base, BFD: Bituminous Full Depth, } \\
\text { BOB: Bituminous Over Bituminous) } \\
0=\text { otherwise }\end{array}$ \\
\hline Bituminous $_{2}$ & $\begin{array}{l}\text { Indicator, } 1=\text { pavement type is BOC, (BOC: Bituminous Over Concrete) } \\
0=\text { otherwise }\end{array}$ \\
\hline Concrete & $\begin{array}{l}\text { Indicator, } 1=\text { pavement type is Concrete, (CD: Concrete Doweled, CRC: Continuously Reinforced Concrete, CU: } \\
\text { Concrete Undoweled) } \\
0=\text { otherwise }\end{array}$ \\
\hline $\begin{array}{l}\text { Year }_{2003^{-}} \\
\text {Year }_{2014}\end{array}$ & $\begin{array}{l}\text { Indicator, } 1=\text { crash year is each year (2003 to 2014), } \\
0=\text { otherwise }\end{array}$ \\
\hline Weekend & $\begin{array}{l}\text { Indicator, } 1=\text { crash date is Saturday or Sunday, } \\
0=\text { otherwise }\end{array}$ \\
\hline Curve & $\begin{array}{l}\text { Indicator, } 1=\text { horizontal alignment of crash location is curve, } \\
0=\text { otherwise }\end{array}$ \\
\hline Grade & $\begin{array}{l}\text { Indicator, } 1=\text { vertical alignment of crash location is grade, } \\
0=\text { otherwise }\end{array}$ \\
\hline Hillcrest & $\begin{array}{l}\text { Indicator, } 1=\text { vertical alignment of crash location is hillcrest, } \\
0=\text { otherwise }\end{array}$ \\
\hline Sag & $\begin{array}{l}\text { Indicator, } 1=\text { vertical alignment of crash location is sag, } \\
0=\text { otherwise }\end{array}$ \\
\hline Wet & $\begin{array}{l}\text { Indicator, } 1=\text { road surface of crash location is wet, } \\
0=\text { otherwise }\end{array}$ \\
\hline Snow & $\begin{array}{l}\text { Indicator, } 1=\text { road surface of crash location is snow, } \\
0=\text { otherwise }\end{array}$ \\
\hline$S L R$ & $\begin{array}{l}\text { Indicator, } 1=\text { crash date is during Spring Load Restrictions, } \\
0=\text { otherwise }\end{array}$ \\
\hline Rushhour & $\begin{array}{l}\text { Indicator, } 1=\text { crash date is during rush hour, } \\
0=\text { otherwise }\end{array}$ \\
\hline$X X: \mathrm{RQI}$ & Interaction term, RQI: Ride quality index \\
\hline
\end{tabular}

We also add several independent variables about crash conditions (date, road characteristics, and road surface) to the model. To illustrate the coding, as shown in, horizontal alignment of crash location is both 'straight' and 'curve' in this segment, and vertical alignment of crash location is 'level', 'grade' and 'hillcrest'. In this case, the value of 'curve', 'grade' and 'hillcrest' are 1 while the value of 'sag' is 0. We code for 'Spring Load Restrictions' (SLR) (March to May) when roads are weak during spring due to the spring thaw, therefore the local authority has begun Spring Load Weight Restrictions (SLR) to reduce road damage (MnDOT n.d.). We code for peak travel periods, 'Rush hour' is defined as 6 am to 9 am and $3 \mathrm{pm}$ to $7 \mathrm{pm}$ (Brown 2013).

We analyze the relationship with a Negative Binomial Regression using the statistical package $R$ version 3 .

\section{FINDINGS}

Table 3 shows regression results. 
Table 3: Negative Binomial Regression: Number of crashes by type by year

\begin{tabular}{|c|c|c|c|c|c|c|c|c|c|}
\hline & \multicolumn{3}{|c|}{ Fatal } & \multicolumn{3}{|c|}{ Injury } & \multicolumn{3}{|c|}{ Property damage } \\
\hline & Estimate & $z$ value & & Estimate & $z$ value & & Estimate & $z$ value & \\
\hline (Intercept) & $-6.398 \mathrm{E}+00$ & -39.368 & $* * *$ & $-3.024 E+00$ & -104.461 & $* * *$ & $-2.336 E+00$ & -105.923 & $* * *$ \\
\hline Trucks & $-1.836 \mathrm{E}-02$ & -3.492 & $* * *$ & $-2.692 \mathrm{E}-02$ & -25.887 & $* * *$ & $-1.721 \mathrm{E}-02$ & -22.090 & *** \\
\hline Traffic & $-1.636 \mathrm{E}-05$ & -5.938 & $* * *$ & $4.788 \mathrm{E}-06$ & 11.105 & $* * *$ & $1.100 \mathrm{E}-05$ & 32.570 & $* * *$ \\
\hline Traffic $^{2}$ & $8.180 \mathrm{E}-11$ & 4.106 & $* * *$ & $2.979 \mathrm{E}-12$ & 0.985 & & $-2.516 \mathrm{E}-11$ & -10.391 & $* * *$ \\
\hline Length & 7.312E-01 & 6.918 & $* * *$ & 1.927E-01 & 10.644 & $* * *$ & $5.968 \mathrm{E}-02$ & 4.251 & *** \\
\hline Bituminous $_{1}$ & $6.024 \mathrm{E}-02$ & 0.268 & & $1.710 \mathrm{E}-01$ & 4.036 & $* * *$ & $1.951 \mathrm{E}-01$ & 5.946 & *** \\
\hline Bituminous $_{2}$ & $-3.668 \mathrm{E}-01$ & -1.122 & & 4.083E-01 & 7.687 & $* * *$ & $6.599 \mathrm{E}-01$ & 16.297 & *** \\
\hline Year $_{2003}$ & $2.462 \mathrm{E}-01$ & 2.216 & * & $1.396 \mathrm{E}-01$ & 6.566 & $* * *$ & $3.620 \mathrm{E}-02$ & 2.208 & * \\
\hline Year $_{2004}$ & $1.746 \mathrm{E}-01$ & 1.551 & & $1.772 \mathrm{E}-01$ & 8.407 & $* * *$ & 1.171E-01 & 7.231 & *** \\
\hline Year $_{2005}$ & $2.221 \mathrm{E}-01$ & 1.987 & * & $1.255 \mathrm{E}-01$ & 5.893 & $* * *$ & $6.115 \mathrm{E}-02$ & 3.744 & *** \\
\hline Year $_{2006}$ & $1.050 \mathrm{E}-01$ & 0.904 & & $1.679 \mathrm{E}-01$ & 7.764 & $* * *$ & $1.040 \mathrm{E}-01$ & 6.260 & *** \\
\hline Year $_{2007}$ & $1.785 \mathrm{E}-01$ & 1.561 & & $1.355 \mathrm{E}-01$ & 6.297 & $* * *$ & $-1.400 \mathrm{E}-02$ & -0.838 & \\
\hline Year $_{2009}$ & $-2.950 \mathrm{E}-02$ & -0.242 & & 7.359E-02 & 3.367 & $* * *$ & $-4.565 \mathrm{E}-02$ & -2.716 & ** \\
\hline Year $_{2010}$ & $-1.403 \mathrm{E}-01$ & -1.125 & & 1.107E-01 & 5.102 & $* * *$ & $-1.350 \mathrm{E}-02$ & -0.808 & \\
\hline Year $_{2011}$ & -1.817E-01 & -1.444 & & $5.851 \mathrm{E}-02$ & 2.682 & ** & $-4.176 \mathrm{E}-02$ & -2.497 & * \\
\hline Year $_{2012}$ & $-1.850 \mathrm{E}-01$ & -1.455 & & $1.264 \mathrm{E}-01$ & 5.738 & $* * *$ & 3.719E-02 & 2.194 & * \\
\hline Year $_{2013}$ & $-1.907 \mathrm{E}-01$ & -1.541 & & 7.143E-03 & 0.330 & & $-2.421 \mathrm{E}-02$ & -1.475 & \\
\hline Weekend & $6.966 \mathrm{E}-01$ & 2.017 & * & $6.883 \mathrm{E}-01$ & 11.784 & $* * *$ & $6.545 \mathrm{E}-01$ & 15.061 & $* * *$ \\
\hline Curve & $-2.234 \mathrm{E}-01$ & -0.734 & & $-1.131 \mathrm{E}-02$ & -0.221 & & $-4.729 \mathrm{E}-02$ & -1.185 & \\
\hline Grade & 7.971E-01 & 2.451 & * & $1.809 \mathrm{E}-01$ & 3.394 & $* * *$ & 3.014E-01 & 7.356 & $* * *$ \\
\hline Hillcrest & 5.427E-01 & 1.219 & & $2.991 \mathrm{E}-01$ & 4.064 & $* * *$ & $3.445 \mathrm{E}-01$ & 5.838 & $* * *$ \\
\hline Sag & $-8.215 \mathrm{E}-02$ & -0.170 & & 3.390E-01 & 4.396 & $* * *$ & 3.498E-01 & 5.635 & $* * *$ \\
\hline Wet & $-3.373 E-02$ & -0.104 & & 7.134E-01 & 13.210 & $* * *$ & 6.567E-01 & 15.924 & $* * *$ \\
\hline Snow & $6.920 \mathrm{E}-01$ & 2.181 & * & $3.621 \mathrm{E}-01$ & 6.799 & $* * *$ & 4.471E-01 & 10.944 & $* * *$ \\
\hline$S L R$ & 3.394E-02 & 0.102 & & 7.174E-01 & 12.400 & $* * *$ & 7.906E-01 & 18.232 & $* * *$ \\
\hline Rushhour & 8.613E-01 & 2.298 & * & $1.598 \mathrm{E}+00$ & 23.750 & $* * *$ & $1.759 \mathrm{E}+00$ & 35.188 & $* * *$ \\
\hline Bituminous $_{1}: R Q I$ & $8.621 \mathrm{E}-03$ & 0.125 & & $-1.959 \mathrm{E}-02$ & -1.464 & & $-5.980 \mathrm{E}-02$ & -5.780 & $* * *$ \\
\hline RQI:Curve & 2.784E-01 & 2.951 & ** & $6.980 \mathrm{E}-02$ & 4.268 & $* * *$ & $6.846 \mathrm{E}-02$ & 5.368 & *** \\
\hline RQI: Grade & $-1.873 \mathrm{E}-01$ & -1.861 & & $6.308 \mathrm{E}-03$ & 0.371 & & $-6.614 \mathrm{E}-03$ & -0.505 & \\
\hline RQI : Hillcrest & $-1.118 \mathrm{E}-01$ & -0.777 & & $-4.066 \mathrm{E}-02$ & -1.672 & . & $-5.272 \mathrm{E}-02$ & -2.704 & ** \\
\hline RQI:Sag & $9.596 \mathrm{E}-02$ & 0.623 & & $-5.401 \mathrm{E}-02$ & -2.126 & * & $-5.011 \mathrm{E}-02$ & -2.448 & * \\
\hline RQI: Wet & $5.531 \mathrm{E}-02$ & 0.554 & & $-3.886 \mathrm{E}-02$ & -2.270 & * & $-1.769 \mathrm{E}-02$ & -1.346 & \\
\hline
\end{tabular}


Fatal

Estimate

$R Q I$ :Snow

$R Q I: S L R$

RQI : Rushhour

AIC

$-2.395 \mathrm{E}-01$
$1.436 \mathrm{E}-01$

$1.082 \mathrm{E}-01$

17,311
Injury

Property damage
Estimate $\quad \mathrm{z}$ value

$2.036 \mathrm{E}-02$

$-2.290 \mathrm{E}-02$

$-5.638 \mathrm{E}-02$
Legend: . $\mathrm{p}<0.1 ;^{*} \mathrm{p}<0.05 ;{ }^{* *} \mathrm{p}<0.01{ }^{* * *} \mathrm{p}<0.001$
Estimate

8.254E-02

$-5.142 \mathrm{E}-02$

$-1.114 \mathrm{E}-01$

260,910 $z$ value

$-7.139$

***

*** 
Good pavement quality is associated with lower crash rates in several conditions:

- Snow (RQI : Snow) for fatal crashes,

- Asphalt over concrete (Bituminous $2: R Q I)$ and sags ( $R Q I: S a g$ ) for injury and property damage crashes,

- Wet roads (RQI : Wet) for injury crashes, and

- Crests (RQI : Hillcrest), and spring load restrictions (RQI :SLR) for property damage crashes.

The $\mathrm{z}$-value from the model indicates that there are significant differences across pavement type.

However, counter-intuitively perhaps, for all three crash types, good pavement quality on curves ( $R Q I$ : Curve) increases number of crashes compared with curves in general or good pavement quality in general. Perhaps poor pavement quality on curves positively affects driver alertness. Speed limit, speed compliance, and curve geometry play important role in these types of crashes.

Similarly for property damage crashes, good pavement quality in snow ( $R Q I: S n o w)$ is associated with an increase in crashes.

Bituminous pavement material (Bituminous $s_{1}$ and Bituminous $s_{2}$ ) is associated with a higher number of injury and property damage crashes. The causality might not be that bituminous pavement causes crashes, rather it could be that concrete surfaced roads, which are fewer in number and tend to serve higher levels of traffic, are built to a different or more modern standard. However there is no evidence to support or refute this speculation. Future research can try to disentangle this question by examining otherwise identical road sections that changed pavement material. In winter conditions, ice (black ice) conditions occur, and the effects of de-icing chemicals on different surfaces might also factor.

Our other findings are as follows:

- As would be expected, in all cases segment length is positive, longer segments have more opportunities for crashes.

- For all cases, percentage trucks is negative, indicating number of crashes drop on facilities with a higher share of trucks. Roads serving a higher share of trucks may be built to a higher standard than other roads, so the causality might not be that trucks reduce crashes.

- The relationship between traffic and crashes is more complex. We modeled this parabolically, including both Traffic and Traffic ${ }^{2}$. For fatal crashes, at lower levels of traffic, crashes decline with increasing 
traffic, but beyond a threshold they increase. In contrast for property damage crashes, the relationship is the reverse, and for injury crashes, crashes increase with number of vehicles on the road.

- During rush hour periods crashes of all types increase due to the increased opportunity for vehicular interaction.

- Injury and property damage crashes generally decrease over time (compared with 2014).

- Crashes of all types increase on weekends, on grades, and in snow.

- Injury and property damage crashes increase on hillcrests, sags, wet conditions, and during the Spring Load Restrictions period. 


\section{REFERENCES}

Abdel-Aty, Mohamed, and Fathy Abdalla. 2004. "Linking Roadway Geometrics and Real-Time Traffic Characteristics to Model Daytime Freeway Crashes: Generalized Estimating Equations for Correlated Data." Transportation Research Record:Journal of the Transportation Research Board, no. 1897: 106-15.

Al-Masaeid, Hashem R. 1997. “Impact of Pavement Condition on Rural Road Accidents.” Canadian Journal of Civil Engineering 24 (4): 523-31.

Brown, Heather. 2013. “Good Question: When Is Rush Hour?” 2013.

http://minnesota.cbslocal.com/2013/07/29/good-question-when-is-rush-hour.

Buddhavarapu, Prasad, Ambarish Banerjee, and Jorge A Prozzi. 2013. "Influence of Pavement Condition on Horizontal Curve Safety." Accident Analysis Ev Prevention 52: 9-18.

Chan, Chun Yip, Baoshan Huang, Xuedong Yan, and Stephen Richards. 2009. "Relationship Between Highway Pavement Condition, Crash Frequency, and Crash Type.” Journal of Transportation Safety E'Security 1 (4): 268-81.

Elghriany, Ahmed F. 2016. "Investigating Correlations of Pavement Conditions with Crash Rates on In-Service US Highways.” PhD thesis, University of Akron.

Lee, Jaeyoung, BooHyun Nam, and Mohamed Abdel-Aty. 2015. "Effects of Pavement Surface Conditions on Traffic Crash Severity.” Journal of Transportation Engineering 141 (10): 04015020.

Merritt, David K, Craig Lyon, Bhagwant Persaud, and others. 2015. "Evaluation of Pavement Safety Performance.” United States. Federal Highway Administration.

MnDOT. n.d. "Spring Load Restrictions.” Accessed May 3, 2016. http://dotapp7.dot.state.mn.us/ research/seasonal_load_limits/thawindex/slr_introduction.pdf.

Najafi, Shahriar, Gerardo W Flintsch, and Alejandra Medina. 2017. "Linking Roadway Crashes and Tire--Pavement Friction: A Case Study." International Journal of Pavement Engineering 18 (2): 119-27.

Sutton, Tim, and Otto Dassau. 2015. “QGIS.” http://www.qgis.org/en/site/index.html.

Vinayakamurthy, Mounica, Michael Mamlouk, and PE Shane Underwood. 2017. "Effect of Pavement Condition on Accident Rate.” Master of Science, Arizona State 452. 